\title{
Demonstration of a novel technique to quantitatively assess inflammatory mediators and cells in rat knee joints Nicola J Barton*1, David A Stevens ${ }^{2}$, Jane P Hughes ${ }^{2}$, Adriano G Rossi ${ }^{3}$, Iain P Chessell ${ }^{2}$, Alison J Reeve ${ }^{2}$ and Daniel S McQueen ${ }^{1}$
}

Address: ${ }^{1}$ Division of Neuroscience, University of Edinburgh, Medical College, 1 George Sq, Edinburgh, EH8 9JZ, UK, ${ }^{2}$ Neurology CEDD, GlaxoSmithKline R\&D Ltd, Harlow, Essex CM19 5AW, UK and ${ }^{3}$ MRC Centre for Inflammation Research, The Queens Medical Research Institute, University of Edinburgh, EH16 4TJ, UK

Email: Nicola J Barton* - N.J.Barton@sms.ed.ac.uk; David A Stevens - David.A.Stevens@gsk.com; Jane P Hughes - Jane.P.Hughes@gsk.com; Adriano G Rossi - Adriano.Rossi@ed.ac.uk; Iain P Chessell - Iain.P.Chessell@gsk.com; Alison J Reeve - Alison.J.Reeve@gsk.com; Daniel S McQueen - D.S.McQueen@ed.ac.uk

* Corresponding author

Published: 13 June 2007

Journal of Inflammation 2007, 4:13 doi:10.1 186/1476-9255-4-13

This article is available from: http://www.journal-inflammation.com/content/4/1/13

(c) 2007 Barton et al; licensee BioMed Central Ltd.

This is an Open Access article distributed under the terms of the Creative Commons Attribution License (http://creativecommons.org/licenses/by/2.0), which permits unrestricted use, distribution, and reproduction in any medium, provided the original work is properly cited.
Received: 19 December 2006

Accepted: 13 June 2007

\begin{abstract}
Background: The inflammation that accompanies the pain and swelling associated with osteo- and rheumatoid arthritis is mediated by complex interactions of inflammatory mediators. Cytokines play a pivotal role in orchestrating many of these processes, including inflammatory cell recruitment, adhesion and activation. In addition, prostaglandins are secreted into the synovial cavity and are involved in perpetuation of local inflammation, vasodilatation and vasoconstriction, and also with bone resorption. Pre-clinical models have been developed in order to correlate to the human disease and principle among these is the adjuvant-induced arthritis model in the rat.
\end{abstract}

Methods: We have developed a technique to quantitatively assess the contents of synovial fluid samples from rat joints. Two needles joined together are inserted into the knee joint of anaesthetised rats and connected to a Watson-Marlow perfusion pump. Sterile saline is infused and withdrawn at $100 \mu \mathrm{l} \mathrm{min}{ }^{-1}$ until a $250 \mu \mathrm{l}$ sample is collected.

Results: Our results demonstrate up to 125 fold increases in synovial ILI $\alpha$ and ILI $\beta$ concentrations, approximately 30 fold increases in levels of IL6 and ILI0 and a 200-300 fold elevation in synovial concentrations of TNF $\alpha$ during FCA-induced experimental arthritis. Finally, this novel technique has demonstrated a dose-response relationship between FCA and the total cell counts of synovial perfusates.

Conclusion: In summary, this new technique provides a robust method for quantifying inflammatory mediators and cells from the synovial cavity itself, thereby detailing the inflammatory processes from within the capsule and excluding those processes occurring in other tissues surrounding the entire articulation. 


\section{Background}

Inflammatory joint diseases such as rheumatoid arthritis (RA) are regulated by complex interactions involving many mediators, such as prostanoids and cytokines. The infiltration of cells into the synovial tissue and joint space is another key characteristic of synovitis, which combined with release of these mediators and degradative enzymes, eventually leads to cartilage and bone destruction (for reviews see [1]).

Measuring the levels of these mediators of inflammation in the synovial fluid from patients can provide information about the underlying pathophysiology of joint disease [2], for example the level of severity and current activity [3-5] as well as inter-individual variations in disease [6] and effectiveness of drug-treatments (for review see [7]). Furthermore changes occurring in the synovial fluid can be used as biomarkers of disease; this has already been demonstrated in RA patients with plasma levels of inflammatory proteins $[8,9]$.

Human joint fluid samples have been taken and analysed for inflammatory mediator content from both healthy volunteers and patients with joint diseases. These studies revealed the importance of particular cytokines, including Tumour Necrosis Factor (TNF) $\alpha$, Interleukin (IL) $1 \beta$, and IL6, which are now targets for disease-modifying antirheumatic drugs (DMARDs; for review see $[10,11])$. Furthermore increases in virtually all the prostanoids have been detected from these samples $[12,13]$, but notably Prostaglandin $\mathrm{E}_{2}\left(\mathrm{PGE}_{2}\right)$, which has been associated with erosion of bone and cartilage in RA [14-17].

Although studies have investigated the fluid taken from joints, most research has focused on the inflammatory mediators within the synovial membrane, rather than those released into the intra-articular space. One reason for this is the technical difficulty of trying to assess cytokine levels in such a viscous material as synovial fluid. Several studies have assessed cytokine gene expression levels in the synovial membrane, rather than the actual protein content, both in human clinical samples $[18,19]$ and in animal models of arthritis [20-22]. In addition, PGE synthase, the enzyme responsible for the conversion of cyclooxygenase-derived $\mathrm{PGH}_{2}$ to $\mathrm{PGE}_{2}$ has been detected in synovial tissues of patients with RA [23].

The early time course of release of key mediators cannot be determined using human synovial fluid samples, as patients rarely report to the clinic until the disease has progressed and is causing chronic pain and swelling [24]. Even then, repeated sampling from individuals is difficult, and most patients are prescribed drugs, to improve their symptoms and quality of life, which interfere with inflammatory regulatory processes and cytokine expression.
Therefore by using animal models of disease, the early events of inflammation can be elucidated, and the effects of drugs on inflammatory markers can be measured under controlled conditions.

Rat adjuvant-induced unilateral arthritis is a well established RA disease model. [25-27] and use of this model has gone a long way in aiding the understanding of the time-course of the pathology in clinical RA. The model closely mimics the pathology of human RA, including histopathological changes, cell infiltration, hypersensitivity and swelling of the affected joint [28-30]. Previous studies in animal models of joint inflammation have investigated the time course of cytokine protein or gene expression using homogenates of whole rat joints or paws post mortem [20-22,31-33]. A major limitation of these studies is that such sampling always includes bone, synovial tissue, synovial fluid and surrounding muscles and connective tissue, which will not allow the origin of any analytes to be determined. Others have surgically dissected and lavaged knee joints in order to collect the synovial fluid from dead animals [34-36]. However, this does not allow for acute repeated sampling from the same animal over a period of up to a day to determine the affect of drugs on the levels of inflammatory mediators, or the acute effect of an inflammatory insult on inflammatory processes in the synovial cavity, a significant benefit of the perfusion method described here. A further study used an in vivo microdialysis procedure to determine the levels of inflammatory mediators in the synovial fluid of rats with adjuvant induced polyarthritis [37]. However, the apparatus used for this had limitations, for example the molecular weight cut-off of the microdialysis membrane was $50 \mathrm{kD}$, and therefore potentially underestimated the levels of IL1 $\beta$ in the joints. Furthermore, this limits the molecules that could be assessed by this method, which is in contrast to the present method, in which there is no limit to the size of molecules collected. The perfusion technique described in the present study also allows for the collection of cells from the joint space. As yet, no studies appear to have been carried out by perfusing saline through the intact joint space and collecting samples of cells and mediators from intact anaesthetised animals. The primary aim of this study was to develop a perfusion method to sample only the synovial fluid. A secondary aim was to study the effects of a joint insult on the intra-articular cytokine concentrations and cell infiltrate levels associated with adjuvant-induced arthritis in the joint space were also measured, as these are known key mediators in human RA conditions.

\section{Methods}

Experiments were performed in accordance with Home Office regulations and within UK animal welfare guidelines, and received Local Ethics Committee approval. 
Male Wistar rats (Charles River, UK; initial weight ranges 240-290 g) were used. Rats were housed four to a cage in a 12-h light: dark environment and were given free access to standard animal feed and water for the duration of the study.

\section{I Arthritis induction}

Briefly, rats (8) were transiently anaesthetised using 3\% halothane in oxygen. The left knee was injected with 150 $\mu \mathrm{l}$ of Freund's Complete Adjuvant (FCA; $1 \mathrm{mg} \mathrm{ml}^{-1}$ Mycobacterium tuberculosis, Sigma, UK; i.art). A further 3 rats received a higher dose of FCA $(500 \mu \mathrm{g})$, in order to assess the effect of adjuvant dose on inflammatory cell recruitment and mediator release into the joint space $(100 \mu \mathrm{l} ; 5$ mg ml-1 Mycobacterium tuberculosis, MAFF, UK; i.art). Only 3 rats were used for this part of the study, as it was designed as a pilot study to determine whether differences in the number of inflammatory cells and mediators present in the knee joint were evident between normal animals and those injected with the two doses of adjuvant using this new technique. The right joints were untreated. Animals were then allowed to recover from the anaesthesia.

\subsection{Perfusion of joint space and analysis of samples}

\subsection{The perfusion needles}

A needle perfusion system was constructed by binding a 25- and a 23-gauge needle together using epoxy putty, with the bevels of the needles positioned on the outside edges facing away from one another (see Figure 1). The tips of the needles were set 1-1.5 mm apart.

\subsubsection{Perfusion of knee joints}

Rats were anaesthetised with urethane (ethyl carbamate; $0.6 \mathrm{ml} 100 \mathrm{~g}^{-1}$ body weight; $25 \% \mathrm{w} \mathrm{v}^{-1}$ solution; single i.p.

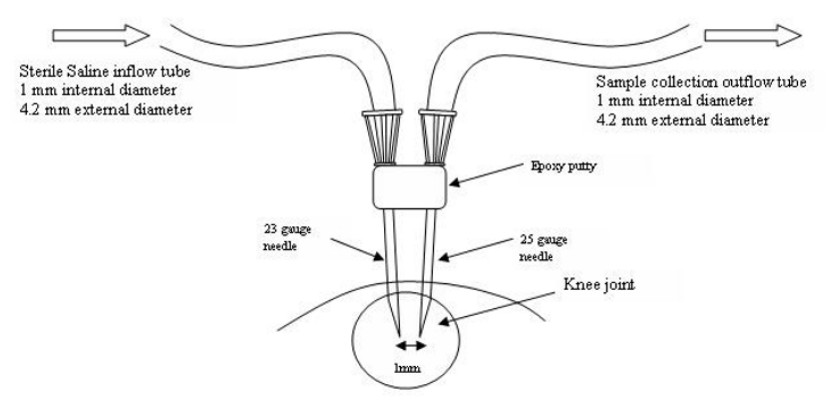

\section{Figure I}

The perfusion needles and the perfusion system managing inflow and outflow from the knee joint space. A WatsonMarlow pump controlled the rate of saline infusion and sample extraction $\left(100 \mu \mathrm{l} \mathrm{min}^{-1}\right)$ from the joint. After the knee was secured to prevent movement of the limb, needles were inserted into the knee joint through the patella tendon. injection). Once fully anaesthetised the animal was laid on its back on an automated heating blanket (Harvard Apparatus Limited, UK) and its core body temperature maintained at $37^{\circ} \mathrm{C}$ via a thermistor probe positioned in the rectum.

The limbs of the rat were flexed over a $20 \mathrm{ml}$ glass vial, with the patella facing directly upwards for insertion of the perfusion needles, and the limb was secured in place with tape. The 23-gauge needle was connected to a Watson-Marlow roller pump via silicone rubber perfusion tubing (internal diameter $1 \mathrm{~mm}$, external diameter 4.2 $\mathrm{mm}$, Watson Marlow, UK). Sterile saline was infused at a constant rate of $100 \mu \mathrm{l} \mathrm{min}{ }^{-1}$. After infusion of $100 \mu \mathrm{l}$ of vehicle (sterile saline), the outflow tubing was connected to the 25-gauge needle, to minimise pressure build-up within the joint space. Fluid was infused and withdrawn at a constant rate until a $250 \mu \mathrm{l}$ basal sample was collected in a $1.5 \mathrm{ml}$ centrifuge tube. Samples were immediately frozen at $-20^{\circ} \mathrm{C}$.

\subsubsection{Cytokine assay of joint samples}

Luminex assay

Samples from the studies investigating the effects of anaesthetic on joint cytokine levels $(n=10)$ and the differences between normal $(\mathrm{n}=10)$, high dose FCA-injected $(n=3)$ and low dose FCA-injected joints $(n=8)$ were analysed using a multi-cytokine bead array detection system capable of detecting rat IL1 $\alpha$, IL1 $\beta$, IL2, IL4, IL6, IL10, Interferon (IFN) $\gamma$, Granulocyte Macrophage-Colony Stimulating Factor (GM-CSF) and TNFa, according to the manufacturers instructions (Bio-Rad cytokine rat 9-plex, Biorad, USA). Briefly, a monoclonal antibody directed against the desired analyte was covalently coupled to dyed $5.5 \mu \mathrm{m}$ polystyrene beads $\left(2.5 \times 10^{6}\right.$ beads $\mathrm{ml}^{-1}$ cytokine $\left.{ }^{1}\right)$. The conjugated beads were exposed to $50 \mu \mathrm{l}$ of sample or standard solutions containing a known amount of cytokine, in a 96-well filter plate and incubated overnight at $4^{\circ} \mathrm{C}$, protected from light. After a series of washes and vacuum filtration to remove unbound protein, a biotinylated detection antibody specific for a different epitope on the analyte was added to the reaction. After incubation, the unbound antibody was removed; the reaction mixture was detected by the addition of streptavidin-phycoerythrin (streptavidin-PE), which binds to the biotinylated detection antibodies. Following a further series of washes and vacuum filtration, the beads were re-suspended in $200 \mu \mathrm{l}$ 5\% BSA in PBS; the plate was stored at $4{ }^{\circ} \mathrm{C}$ in the dark until analysis. The reaction mixture was read using a Luminex Data Collector in a Luminex 100 flow cytometer (Luminex, USA). The minimum detection limit of the assay was $2 \mathrm{pg} \mathrm{ml}^{-1}$ for each mediator measured. Any values lower than these levels were classed as 0 for the purposes of this study. 


\section{Luminex data analysis}

Excel data files were generated containing individual bead numbers and the associated median fluorescence intensities. Standard curves were plotted to calculate the relative amount of each cytokine in samples, using the aliquoted serial dilutions of a positive control solution for calibration. Unknown sample cytokine concentrations were calculated from the curve.

\section{ELISA assay}

The levels of TNF $\alpha$ and IL $\beta$ in samples from studies investigating the effects of the needles $(n=6)$, and leakage of infusion from the joint cavity $(n=2)$ were measured using commercially available ELISA kits that specifically recognize the rat cytokines (BioSource International, Camarillo, USA) according to the manufacturer's instructions. Briefly, $100 \mu \mathrm{l}$ aliquots of sample were pipetted into the wells of a microtiter plate pre-coated with an antibody specific for rat IL-1 $\beta$ or TNF $\alpha$ and incubated for $3 \mathrm{~h}$ at room temperature. After washing, a different biotinylated anti-rat IL- $1 \beta$ or TNF $\alpha$ antibody was added and incubated at ambient temperature for $1 \mathrm{~h}$. Streptavidin-peroxidase was added and incubated for $30 \mathrm{~min}$. After a third incubation and washing to remove all unbound enzyme, colour was developed by addition of stabilized chromogen (tetramethylbenzidine), a stop solution added and the intensity of the coloured product quantified spectrophotometrically at $450 \mathrm{~nm}$. The minimum detection limit of the assay was $2 \mathrm{pg} \mathrm{ml}^{-1}$.

\subsection{Study design}

\subsection{Anaesthetic effects}

In order to determine what effect anaesthetic agents had on inflammatory mediators in joints, control experiments were carried out. Firstly, five naive rats were anaesthetised with urethane (ethyl carbamate; $0.6 \mathrm{ml} 100 \mathrm{~g}^{-1}$ body weight; $25 \% \mathrm{w} \mathrm{v}^{-1}$ solution; single i.p. injection), and five further rats with sodium pentobarbital $\left(1 \mathrm{ml} \mathrm{kg}^{-1}\right.$ body weight; $60 \mathrm{mg} \mathrm{ml}^{-1}$ solution; single i.p. injection maintained with i.v. $375 \mu \mathrm{h} \mathrm{hr}^{-1} 20 \mathrm{mg} \mathrm{ml}^{-1}$ solution of pentobarbital). No other procedures were carried out for 7 hours, at which point perfusion needles were inserted into both knee joints and a $250 \mu \mathrm{l}$ sample collected. The sample was frozen immediately at $-20^{\circ} \mathrm{C}$, and later assayed using the Luminex assay.

\subsubsection{Needle effects}

In order to determine what effects inserting the perfusion needles had on synovial cytokine concentrations, an experiment was carried out in which six animals were anaesthetised with urethane (as described above), and the perfusion needles inserted into both knee joints and held in position for 7 hours, at which time a $250 \mu$ l sample was collected. The sample was frozen immediately at $-20^{\circ} \mathrm{C}$, and later assayed using an ELISA.

\subsubsection{Perfusion effects on the concentration of analyte}

Two naïve rats were anaesthetised with urethane (as described above) and a basal sample taken immediately. Then 1000 pg recombinant rat IL1 $\beta$ (Bioclone, USA) in $100 \mu \mathrm{l}$ was infused over $1 \mathrm{~min}$. A second sample was taken 1 hour later; this was repeated hourly until 7 hours post-IL1 $\beta$ infusion. The samples were frozen and later assayed for IL1 $\beta$ content using an ELISA, to determine if the sample contained the same amount of IL1 $\beta$ that was initially infused.

\subsubsection{Cytokine levels in normal and FCA-injected joints}

Basal samples from ipsilateral and contralateral joints of 10 normal animals were compared with basal samples from 8 rats which had received i.art low dose FCA (150 $\mu \mathrm{g})$ and 3 that were injected with i.art high dose FCA (500 $\mu \mathrm{g}) 14$ days earlier. Samples $(250 \mu \mathrm{l})$ were collected and frozen for later testing with the Luminex bead array.

\subsubsection{Total cell counts}

Joint perfusion samples were collected from ten naïve rat knee joints, eight $150 \mu \mathrm{g}$ FCA-injected ipsilateral and contralateral joints and three $500 \mu \mathrm{g}$ FCA-injected ipsilateral and contralateral joints. Undiluted samples were viewed by light microscopy in a haemocytometer. If red blood cells were present, or a high number of inflammatory cells, samples were diluted in saline, with added Zappoglobin, as per the manufacturer's instructions (1 drop per $20 \mathrm{ml}$ ).

\subsection{Data Analysis}

Data were collected and analysed using Microsoft Excel and Graphpad Prism software. Results are expressed as mean \pm standard error of the mean (SEM) where appropriate.

\section{Statistics}

The Mann-Whitney U (non-parametric) test was used to analyse differences between groups, which were not normally distributed, or in which the sample size was small. To determine differences between the means of more than two groups a non-parametric one-way analysis of variance (Kruskal-Wallis) test was performed and a post-hoc test (Dunn's) undertaken if the test was significant. In all cases the null hypothesis was rejected at $P<0.05$.

\section{Results}

\section{I Anaesthetic effects}

Samples from naïve animals $(n=5)$ which received no treatment during 7 hours of urethane anaesthesia, showed a slight trend for increased levels of cytokines, but the increases were not statistically significant for IL1 $\alpha$, IL1 $\beta$, IL2, IL4, IL6, IL10, GM-CSF, IFN $\gamma$, or TNF $\alpha$ compared with samples taken from rats immediately after administration of anaesthetic ( $\mathrm{n}=10 ; P>0.05$, Mann Whitney) 
see Table 1. However, in contrast, animals anaesthetised with pentobarbital $(\mathrm{n}=5)$, had significantly higher levels of GM-CSF and TNFo $(P<0.05$, Mann Whitney) after 7 hours, in comparison with naïve joints, see Table 1.

\section{2 Needle effects}

Samples taken from knee joints in which the perfusion needles had been in place for 7 hours while the animal was anaesthetised with urethane $(n=6)$ showed increased levels of TNF $\alpha$, as measured by ELISA, but these were not statistically significant from basal samples from the same rats immediately after needle insertion $(P>0.05$, Mann Whitney). IL1 $\beta$ levels in two joints increased to approximately $40 \mathrm{pg} \mathrm{ml}^{-1}$ over this time period, see Figure 2.

\subsection{Perfusion effects on the concentration of analyte}

Two joint perfusions were carried out to determine if any of the infused solution leaked from the joint space prior to withdrawal of samples. Recombinant rat IL1 $\beta$ (1000 pg), a cytokine known to be detectable by ELISA, was infused into the joint, along with saline, and samples were collected hourly. In both cases the full amount (1000 pg) administered was recovered in the first two samples. However, a greater amount of IL1 $\beta$ was recovered compared to the initial dose administered; Table 2 shows the results.

\subsection{Levels of cytokines in normal and FCA-injected joints}

Fourteen days after rats received $150 \mu \mathrm{g}$ or $500 \mu \mathrm{g}$ FCA i.art ( $\mathrm{n}=8$ and 3 respectively), the ipsilateral joint contained significantly higher levels of IL1 $\alpha$, IL1 $\beta$, IL6 and TNF $\alpha$ compared with samples from naïve joints $(n=10)$, as measured by the Luminex assay $(P<0.05$, Two-way ANOVA; see Figure 3a). The contralateral joints of rats injected with $500 \mu \mathrm{g}$ FCA also contained significantly higher levels of IL $1 \alpha$, IL1 $\beta$, IL6 and TNF $\alpha(P<0.05$, Twoway ANOVA; see Figure 3b).

\subsection{Total cell counts}

Total inflammatory cell counts from normal animals ( $\mathrm{n}=$ $5)$ and those injected with FCA $(n=8) 14$ days prior to sampling are shown in Figure 4 . Normal joints had no cells detectable, whereas all others samples had measurable levels. However, only the $500 \mu \mathrm{g}$ FCA ipsilateral ( $\mathrm{n}=$ 3 ) joints proved to have a significantly greater number of
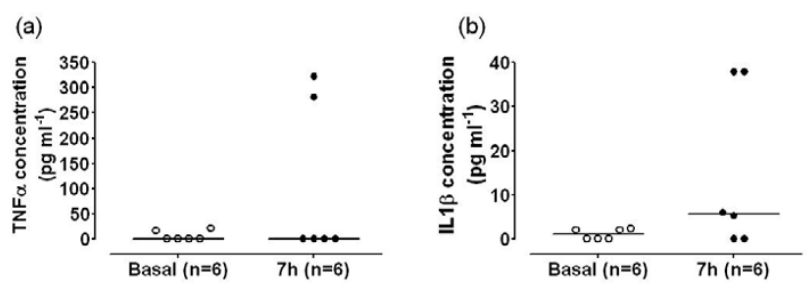

\section{Figure 2}

Levels of (a) TNF $\alpha$ and (b) ILI $\beta$ from joints immediately after needle insertion (basal), and 7 hours later. Cytokines were assayed using an ELISA, and although there was an apparent increase in TNF $\alpha$ concentrations, to approximately $300 \mathrm{pg}$ $\mathrm{ml}^{-1}$ in two samples, this was not statistically significant $(P>$ 0.05, Mann Whitney). The horizontal lines on the graphs represent the median values in each group.

cells than normal joints $\left(4.8 \pm 0.06 \times 10^{6}\right.$ cells $\mathrm{ml}^{-1} ; \mathrm{P}<$ 0.05, Mann Whitney). A dose-response relationship was demonstrated by the total cell count in both ipsilateral and contralateral joints.

\section{Discussion}

The main aim of this study was to develop a method for sampling synovial fluid from the knee joint of anaesthetized rats. The technique was firstly validated by assessing whether any inflammatory response was evoked by the experimental set up, including the anaesthetic or the needles themselves; the efficiency of the system was investigated, i.e. whether any infused solution leaked from the joint space prior to sample extraction. Once the above factors had been assessed, they were taken into consideration when comparing samples from naïve and adjuvantinjected inflamed joints. Finally, the novel perfusion technique was used to quantify inflammatory cell numbers within the rat synovial cavity. This technique proved to be reliable and consistent when perfusing the joint cavity, and regular volumes of sample were easily collected. There were no problems with measuring protein content due to high sample viscosity, and this technique is therefore a valuable addition to protocols which use homogenates of entire joints to assess inflammatory mediator content.

Table I: The effect of anaesthetic on basal levels of cytokines in the joint.

\begin{tabular}{|c|c|c|c|c|c|c|c|c|c|}
\hline & ILI $\alpha$ & ILI $\beta$ & IL2 & IL4 & IL6 & ILIO & GM-CSF & IFN $\gamma$ & TNF $\alpha$ \\
\hline $\begin{array}{l}\text { Basal }(\mathbf{n}=1 \mathbf{0}) \\
\text { Mean } \pm \text { SEM }\end{array}$ & $0.8 \pm 0.5$ & $1.0 \pm 1.0$ & $0.5 \pm 0.5$ & $0.2 \pm 0.2$ & $2.5 \pm 2.5$ & $1.5 \pm 1.0$ & $0 \pm 0$ & $0.1 \pm 0.1$ & $0.2 \pm 0.2$ \\
\hline $\begin{array}{l}\text { Urethane }(\mathbf{n}=\mathbf{5}) \\
\text { Mean } \pm \text { SEM }\end{array}$ & $2.6 \pm 1.1$ & $0 \pm 0$ & $0 \pm 0$ & $0 \pm 0$ & $0 \pm 0$ & $0 \pm 0$ & $1.0 \pm 0.6$ & $0.3 \pm 0.3$ & $36.6 \pm 20.9$ \\
\hline $\begin{array}{l}\text { Pentobarbital }(\mathbf{n}=\mathbf{5}) \\
\text { Mean } \pm \text { SEM }\end{array}$ & $1.4 \pm 0.7$ & $0.2 \pm 0.2$ & $0.1 \pm 0.1$ & $0 \pm 0$ & $0 \pm 0$ & $6.2 \pm 6.2$ & $1.7 \pm 0.4^{*}$ & $0.1 \pm 0.1$ & $44.2 \pm 21.6^{*}$ \\
\hline
\end{tabular}

Levels of nine cytokines in rats anaesthetised for 7 hours with either urethane or pentobarbital, in comparison with samples taken immediately after urethane anaesthesia (basal). Mann Whitney test were performed to determine differences between each anaesthetic and basal levels. Pentobarbital anaesthesia resulted in a significant elevation of GM-CSF and TNF $\alpha$ levels; statistical significance $\mathrm{P}<0.05$ indicated by *. 
Table 2: Perfusion effects on the concentration of analyte.

\begin{tabular}{|c|c|c|c|c|}
\hline & \multicolumn{2}{|l|}{ Animal I } & \multicolumn{2}{|l|}{ Animal 2} \\
\hline & 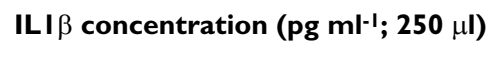 & Amount of ILI $\beta$ (pg) & ILI $\beta$ concentration $\left(\mathrm{pg} \mathrm{ml}^{-1} ; 250 \mu \mathrm{I}\right)$ & $\begin{array}{l}\text { Amount of ILI } \beta \\
(\mathrm{pg})\end{array}$ \\
\hline I hour & 2000 & 500 & 2000 & 500 \\
\hline 2 hour & 2000 & 500 & 2000 & 500 \\
\hline 3 hour & 200 & 50 & 356 & 89 \\
\hline 4 hour & 544 & 136 & 216 & 54 \\
\hline 5 hour & 350 & 87.5 & 210 & 52.5 \\
\hline 6 hour & 458 & 114.5 & 200 & 50 \\
\hline 7 hour & 318 & 79.5 & & \\
\hline
\end{tabular}

Total (pg) $\quad 1467.5$

1245.5

ILI $\beta$ concentrations in each $250 \mu$ sample collected, up to 7 hours post-infusion of ILI $\beta$ ( $1000 \mathrm{pg})$. The amount of ILI $\beta$ protein in each sample was calculated and summed, to show that little or no leakage from the joint space occurred. In fact, more ILI $\beta$ was present than was injected, in both cases as a result of de novo release of endogenous ILI $\beta$ protein.

It was established that the choice of anaesthetic may play a role in initiating an inflammatory response within the knee joints. Urethane, a hypnotic anaesthetic agent commonly used for laboratory animals, resulted in very little change in any of the mediators measured over a 7 hour period. In contrast, pentobarbital (pentobarbitone), a short-acting anaesthetic which must be maintained by i.v infusion, therefore requiring further surgical preparation of the animal, induced increases in GM-CSF and TNF $\alpha$ after continuous administration during the day, perhaps a result of the surgery of the implanted cannulae. It was therefore decided to use urethane for experiments, given that it provides an extended period of anaesthesia with minimal physiological changes [38], without the need for

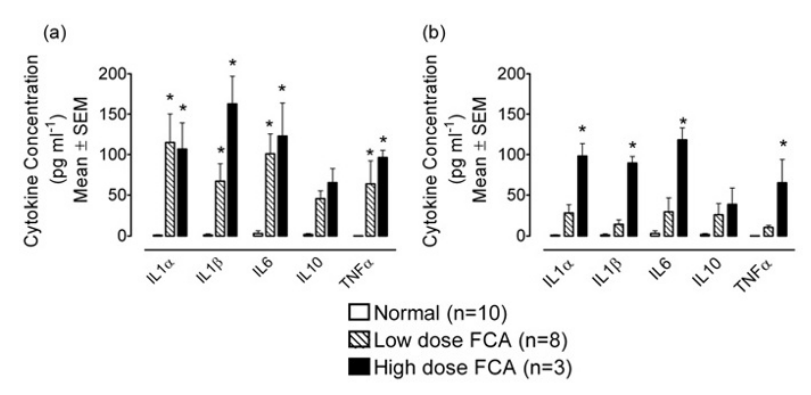

Figure 3

Levels of ILI $\alpha$, ILI $\beta$, IL6, ILI0 and TNF $\alpha$ in (a) ipsilateral and (b) contralateral joints of normal rats and those injected with low (I $50 \mu \mathrm{g} ; \mathrm{n}=8)$ and high $(500 \mu \mathrm{g} ; \mathrm{n}=3)$ dose FCA I4 days earlier. There were negligible levels of any of the mediators measure in naïve joints $(n=10)$, but a significant increase in the expression of ILI $\alpha$, ILI $\beta$, IL6 and TNF $\alpha$ was seen in all ipsilateral inflamed joints and in contralateral joints of rats injected with the high dose FCA $(P<0.05$, Two-way ANOVA; compared with normal joints); statistical significance represented by $*$. invasive surgical preparation. Furthermore, pentobarbital can cause respiratory depression in rats, whereas urethane causes minimal cardiopulmonary disturbances $[38,39]$.

Once it was established that urethane anaesthesia had no adverse effects on the system, it was necessary to evaluate any inflammatory component as a result of the perfusion needles themselves, over a sustained time period of 7 hours. It was noted that a few rats developed increased TNF $\alpha$ or IL1 $\beta$ levels as a result of the needles being maintained within the joint. However, the change occurred in only $20 \%$ of animals, and was not significant; moreover,

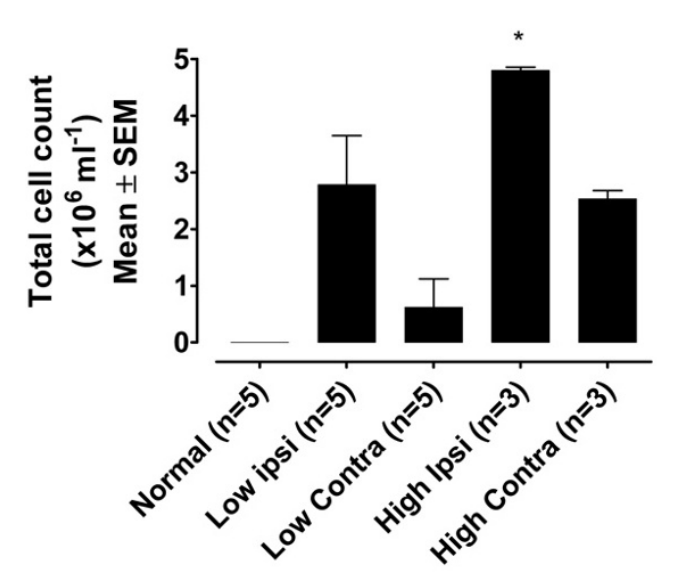

Figure 4

The effects of $150 \mu \mathrm{g}$ (low dose; $\mathrm{n}=5$ ) and $500 \mu \mathrm{g}$ (high dose; $n=3$ ) FCA on total cell count from joint perfusates. Naïve joints contained no cells $(0)$, whereas all other joints contained increased levels, although only high dose ipsilateral joints proved to have significantly raised levels $(P<0.05$, Mann Whitney); statistical significance donated by *. 
the increases in the two mediators did not occur in the same animals.

This study has demonstrated that very little, if any, solution infused into the joint is lost into the surrounding tissue, and can be recovered in full through the effusion tubes. This was confirmed by injection of Evans blue dye into the joint cavity and later dissection of the tissue (data not shown here). Furthermore, there was an increased quantity of IL1 $\beta$ detected in the perfusate collected. Although this study was not designed to show the effects of the protein on the joint, the 1 ng dose of IL $1 \beta$ administered resulted in de novo release of natural IL1 $\beta$, as shown by the fact that elevated levels of IL1 were detected, in addition to the $1 \mathrm{ng}$ dose.

Adjuvant-induced arthritis is a widely used model of inflammatory joint disease, and will be the primary subject of future studies applying this novel perfusion method. It was therefore important that samples collected in this way could detect differences between cytokine levels in naïve joints and FCA-treated joints. Levels of all cytokines measured in this study (IL1 $\alpha$, IL1 $\beta$, IL6, IL10 and TNF $\alpha$ ) showed dramatic increases 14 days after an initial inflammatory insult to the joint, including high and low doses of FCA. Furthermore, the contralateral joint of rats injected with the high dose of FCA also had higher levels of all cytokines measured, illustrating the contralateral effect also noted in the inflammatory cell count study. Finally, this study investigated the total number of white blood cells present in the joint washout samples. Not surprisingly it was observed that FCA-injected joints contained higher levels than normal rat knee joints, as previously shown [40]. However, of particular interest are the cell counts in contralateral, non-injected limbs. Contralateral effects arising from a unilateral insult is a well documented phenomenon. In general, contralateral changes in behaviour, magnitude of biochemical fluctuations or histopathological lesions are less than those observed on the ipsilateral side (for review see [41]). Total cell count data from this study are in agreement with this finding, and although the lower dose of FCA used here does not elicit behavioural signs of inflammation or hypersensitivity in the contralateral joint, there is evidence of infiltration of inflammatory cells.

\section{Conclusion}

In summary, we have demonstrated the use of a novel method for sampling synovial fluid and washing out the joint cavity to collect the "inflammatory soup", and have performed assays to measure levels of cytokines during adjuvant-induced arthritis. This method has the advantage of enabling the contents of synovial fluid to be investigated alone, without the contamination of the surrounding tissue. We have also revealed its value in measuring cellular components of inflammation. In conclusion, as this new method of joint perfusion uses anaesthetised animals, acute effects of anti-inflammatory drugs or novel compounds could be investigated, thus improving the knowledge of how novel drug targets are affecting the inflammatory process.

\section{Competing interests}

The author(s) declare that they have no competing interests.

\section{Authors' contributions}

NJB planned and carried out all in vivo studies, in vitro assays, data interpretation, statistical analysis and compilation of the manuscript. DAS and JPH assisted with the Luminex assay use and data collection, then read and edited the manuscript after completion. AGR assisted with the total inflammatory cell count studies and reviewed and edited the article. IPC, AJR and DSM contributed intellectually to the experimental designs, as well as to structural and editorial aspects of the paper. All authors read and approved the final manuscript.

\section{Acknowledgements}

We would like to thank GlaxoSmithKline for funding these studies and my PhD studentship.

\section{References}

I. Sweeney SE, Firestein GS: Rheumatoid arthritis: regulation of synovial inflammation. Int J Biochem Cell Biol 2004, 36:372-378.

2. Kubota E, Kubota T, Matsumoto J, Shibata T, Murakami KI: Synovial fluid cytokines and proteinases as markers of temporomandibular joint disease. J Oral Maxillofac Surg 1998, 56:192-198.

3. Alstergren P, Ernberg M, Kvarnstrom M, Kopp S: Interleukin- I beta in synovial fluid from the arthritic temporomandibular joint and its relation to pain, mobility, and anterior open bite. J Oral Maxillofac Surg 1998, 56:1059-65; discussion 1066.

4. Chang $\mathrm{H}$, Israel $\mathrm{H}$ : Analysis of inflammatory mediators in temporomandibular joint synovial fluid lavage samples of symptomatic patients and asymptomatic controls. J Oral Maxillofac Surg 2005, 63:76I-765.

5. Rooney M, Symons JA, Duff GW: Interleukin I beta in synovial fluid is related to local disease activity in rheumatoid arthritis. Rheumatol Int 1990, 10:217-219.

6. Ulfgren AK, Grondal L, Lindblad S, Khademi M, Johnell O, Klareskog $\mathrm{L}$, Andersson $\mathrm{U}$ : Interindividual and intra-articular variation of proinflammatory cytokines in patients with rheumatoid arthritis: potential implications for treatment. Ann Rheum Dis 2000, 59:439-447.

7. Barrera P, Boerbooms AM, van de Putte LB, van der Meer JW: Effects of antirheumatic agents on cytokines. Semin Arthritis Rheum 1996, 25:234-253.

8. Eastgate JA, Symons JA, Wood NC, Grinlinton FM, di Giovine FS, Duff GW: Correlation of plasma interleukin I levels with disease activity in rheumatoid arthritis. 1988, 2:706-709.

9. Houssiau FA, Devogelaer JP, Van Damme J, de Deuxchaisnes CN, Van Snick J: Interleukin-6 in synovial fluid and serum of patients with rheumatoid arthritis and other inflammatory arthritides. Arthritis Rheum 1988, 3 I:784-788.

10. Christodoulou C, Choy EH: Joint inflammation and cytokine inhibition in rheumatoid arthritis. Clin Exp Med 2006, 6:13-19.

II. Zwerina J, Redlich K, Schett G, Smolen JS: Pathogenesis of rheumatoid arthritis: targeting cytokines. Ann N Y Acad Sci 2005, | 05 | :7 | 6-729.

12. Egg D: Concentrations of prostaglandins D2, E2, F2 alpha, 6keto-FI alpha and thromboxane $B 2$ in synovial fluid from 
patients with inflammatory joint disorders and osteoarthritis. Z Rheumatol 1984, 43:89-96.

13. Trang LE, Granstrom E, Lovgren O: Levels of prostaglandins F2 alpha and E2 and thromboxane B2 in joint fluid in rheumatoid arthritis. Scand J Rheumatol 1977, 6:15I-154.

14. Dayer JM, Krane SM, Russell RG, Robinson DR: Production of collagenase and prostaglandins by isolated adherent rheumatoid synovial cells. Proc Natl Acad Sci U S A 1976, 73:945-949.

15. Fulkerson JP, Damiano P: Effect of prostaglandin E2 on adult pig articular cartilage slices in culture. Clin Orthop Relat Res 1983:266-269.

16. Robinson DR, Smith H, McGuire MB, Levine L: Prostaglandin synthesis by rheumatoid synovium and its stimulation by colchicine. Prostaglandins 1975, 10:67-85.

17. Robinson DR, Tashjian AH Jr., Levine L: Prostaglandin-stimulated bone resorption by rheumatoid synovia. A possible mechanism for bone destruction in rheumatoid arthritis. J Clin Invest 1975, 56: II8I-1188.

18. Firestein GS, Alvaro-Gracia JM, Maki R: Quantitative analysis of cytokine gene expression in rheumatoid arthritis. J Immunol 1990, 144:3347-3353.

19. Wagner S, Fritz P, Einsele H, Sell S, Saal JG: Evaluation of synovial cytokine patterns in rheumatoid arthritis and osteoarthritis by quantitative reverse transcription polymerase chain reaction. Rheumatol Int 1997, 16:191-196.

20. Patten C, Bush K, Rioja I, Morgan R, Wooley P, Trill J, Life P: Characterization of pristane-induced arthritis, a murine model of chronic disease: response to antirheumatic agents, expression of joint cytokines, and immunopathology. Arthritis Rheum 2004, 50:3334-3345.

21. Rioja I, Bush KA, Buckton JB, Dickson MC, Life PF: Joint cytokine quantification in two rodent arthritis models: kinetics of expression, correlation of mRNA and protein levels and response to prednisolone treatment. Clin Exp Immunol 2004, 137:65-73.

22. Thornton S, Duwel LE, Boivin GP, Ma Y, Hirsch R: Association of the course of collagen-induced arthritis with distinct patterns of cytokine and chemokine messenger RNA expression. Arthritis Rheum 1999, 42:1 109-1।18.

23. Westman M, Korotkova M, af Klint E, Stark A, Audoly LP, Klareskog L, Ulfgren AK, Jakobsson PJ: Expression of microsomal prostaglandin E synthase I in rheumatoid arthritis synovium. Arthritis Rheum 2004, 50:1774-1780.

24. Cohen SB, Katsikis PD, Chu CQ, Thomssen H, Webb LM, Maini RN, Londei M, Feldmann M: High level of interleukin- 10 production by the activated $\mathbf{T}$ cell population within the rheumatoid synovial membrane. Arthritis Rheum 1995, 38:946-952.

25. Bileviciute I, Lundeberg T, Ekblom A, Theodorsson E: Bilateral changes of substance P-, neurokinin A-, calcitonin generelated peptide- and neuropeptide $Y$-like immunoreactivity in rat knee joint synovial fluid during acute monoarthritis. Neurosci Lett 1993, 153:37-40.

26. Billingham ME: Mechanisms and Models of Rheumatoid Arthritis. Edited by: Pettipher ER. London, Academic Press; 1995:389.

27. Mapp PI, Terenghi G, Walsh DA, Chen ST, Cruwys SC, Garrett N, Kidd BL, Polak JM, Blake DR: Monoarthritis in the rat knee induces bilateral and time-dependent changes in substance $P$ and calcitonin gene-related peptide immunoreactivity in the spinal cord. Neuroscience 1993, 57:1091-1096.

28. Donaldson LF, Seckl JR, McQueen DS: A discrete adjuvantinduced monoarthritis in the rat: effects of adjuvant dose. J Neurosci Methods 1993, 49:5-10.

29. Pelegri C, Franch A, Castellote C, Castell M: Immunohistochemical changes in synovial tissue during the course of adjuvant arthritis. J Rheumatol 1995, 22: 124-132.

30. Wilson AW, Medhurst SJ, Dixon Cl, Bontoft NC, Winyard LA, Brackenborough KT, Alba JD, Clarke CJ, Gunthorpe MJ, Hicks GA: An animal model of chronic inflammatory pain: Pharmacological and temporal differentiation from acute models. European Journal of Pain 2006, 10:537-549.

31. Magari K, Miyata S, Nishigaki F, Ohkubo Y, Mutoh S, Goto T: Differential effects of FK506 and methotrexate on inflammatory cytokine levels in rat adjuvant-induced arthritis. J Rheumatol 2003, 30:2193-2200.

32. Marinova-Mutafchieva L, Williams RO, Mason LJ, Mauri C, Feldmann M, Maini RN: Dynamics of proinflammatory cytokine expres- sion in the joints of mice with collagen-induced arthritis (CIA). Clin Exp Immunol 1997, 107:507-5I2.

33. Smith-Oliver T, Noel LS, Stimpson SS, Yarnall DP, Connolly KM: Elevated levels of TNF in the joints of adjuvant arthritic rats. Cytokine 1993, 5:298-304.

34. Keeble JE Curtis, B, Mallaghan, FA \& Brain, SD: The role of sensory nerves in joint inflammation: studies using TRPVI knockout mice. PA2 online 2004, 2:43P.

35. Singh HN, Blancuzzi V, Greenwood S, Skiles JW, O'Byrne EM: Synovial fluid levels of tumor necrosis factor-alpha in the inflamed rat knee: modulation by dexamethasone and inhibitors of matrix metalloproteinase and phosphodiesterase. Inflamm Res 1997, 46 Suppl 2:SI53-4.

36. Vale ML, Benevides VM, Sachs D, Brito GA, da Rocha FA, Poole S, Ferreira SH, Cunha FQ, Ribeiro RA: Antihyperalgesic effect of pentoxifylline on experimental inflammatory pain. $\mathrm{Br} J$ Pharmacol 2004, 143:833-844.

37. Liu SH, Wong CS, Chang DM: Increase Monocyte chemoattractant protein- $I$ in knee joints of rats with adjuvant-induced arthritis: in vivo microdialysis. The journal of rheumatology 2005 , 32:2205-2211.

38. Sapru HN, Krieger AJ: Cardiovascular and respiratory effects of some anesthetics in the decerebrate rat. Eur J Pharmacol 1979 , 53:151-158.

39. Wixson SK, White WJ, Hughes HC Jr., Lang CM, Marshall WK: The effects of pentobarbital, fentanyl-droperidol, ketamine-xylazine and ketamine-diazepam on arterial blood $\mathrm{pH}$, blood gases, mean arterial blood pressure and heart rate in adult male rats. Lab Anim Sci 1987, 37:736-742.

40. Santos L, Tipping PG: Attenuation of adjuvant arthritis in rats by treatment with oxygen radical scavengers. Immunol Cell Biol 1994, 72:406-4I4.

4I. Shenker N, Haigh R, Roberts E, Mapp P, Harris N, Blake D: A review of contralateral responses to a unilateral inflammatory lesion. Rheumatology (Oxford) 2003, 42: 1279-1286.
Publish with BioMed Central and every scientist can read your work free of charge

"BioMed Central will be the most significant development for disseminating the results of biomedical research in our lifetime. "

Sir Paul Nurse, Cancer Research UK

Your research papers will be:

- available free of charge to the entire biomedical community

- peer reviewed and published immediately upon acceptance

- cited in PubMed and archived on PubMed Central

- yours - you keep the copyright

Submit your manuscript here:

http://www.biomedcentral.com/info/publishing_adv.asp
BioMedcentral 